\title{
The potential and hurdles of targeted alpha therapy - clinical trials and beyond
}

\author{
1 IRCM, Institut de Recherche en Cancérologie de Montpellier, Montpellier, France \\ 2 INSERM, U896, Montpellier, France \\ ${ }^{3}$ Université Montpellier 1, Montpellier, France \\ ${ }^{4}$ Institut Régional de Cancérologie de Montpellier, Montpellier, France \\ ${ }^{5}$ Fred Hutchinson Cancer Research Center, Seattle, WA, USA \\ ${ }^{6}$ Department of Oncology, University of Gothenburg, Gothenburg, Sweden
}

Jörgen Elgqvist ${ }^{1,2,3,4}$ *, Sofia Frost ${ }^{5}$, Jean-Pierre Pouget ${ }^{1,2,3,4}$ and Per Albertsson ${ }^{6}$

Edited by:

Søren M. Bentzen, University of Maryland School of Medicine, USA

\section{Reviewed by:}

Joel S. Greenberger, University of

Pittsburgh Medical Center, USA

Anuja Jhingran, MD Anderson Cancer

Center, USA

\section{*Correspondence.}

Jörgen Elgqvist, Institut de

Recherche en Cancérologie de

Montpellier, INSERM, U896,

Université Montpellier 1, Montpellier

F-34298, France

e-mail: jorgen.elgqvist@gu.se
This article presents a general discussion on what has been achieved so far and on the possible future developments of targeted alpha $(\alpha)$-particle therapy (TAT). Clinical applications and potential benefits of TAT are addressed as well as the drawbacks, such as the limited availability of relevant radionuclides. Alpha-particles have a particular advantage in targeted therapy because of their high potency and specificity. These features are due to their densely ionizing track structure and short path length. The most important consequence, and the major difference compared with the more widely used $\beta^{-}$-particle emitters, is that single targeted cancer cells can be killed by self-irradiation with $\alpha$-particles. Several clinical trials on TAT have been reported, completed, or are on-going: four using ${ }^{213} \mathrm{Bi}$, two with ${ }^{211} \mathrm{At}$, two with ${ }^{225} \mathrm{Ac}$, and one with ${ }^{212} \mathrm{~Pb} /{ }^{212} \mathrm{Bi}$. Important and conceptual proof-of-principle of the therapeutic advantages of $\alpha$-particle therapy has come from clinical studies with ${ }^{223}$ Ra-dichloride therapy, showing clear benefits in castration-resistant prostate cancer.

\section{Keywords: targeted alpha therapy, alpha emitters, radionuclide therapy, dosimetry, ovarian cancer, cancer}

\section{INTRODUCTION}

In radioimmunotherapy (RIT), monoclonal antibodies $(\mathrm{mAb})$ are conjugated to radionuclides, which provide a specific internal radiotherapy. The clinical success so far has been achieved with the beta $\left(\beta^{-}\right)$-emitting (electrons) nuclides ${ }^{90} \mathrm{Y}$ and ${ }^{131} \mathrm{I}$, conjugated to anti-CD20 mAb in follicular B-cell non-Hodgkin lymphoma. The lack of success in the adjuvant setting in solid cancer (i.e., with microscopic tumor burden) may be due to the fact that emitted electrons do not deposit their main energy to the micro-metastatic tumor cells where the antibody has bound; rather, the energy (and its effects) will be released along a several millimeter long electron track, i.e., in the surrounding healthy tissue, see Figure 1.

This review concerns targeted alpha $(\alpha)$-particle therapy (TAT), where $\alpha$-emitting nuclides are conjugated to a carrier, normally an antibody. Alpha-particle decay is the release of a heavy and energetic particle, which deposits its energy in a $70-100 \mu \mathrm{m}$ long track, i.e., within microscopic tumor cell clusters. Importantly, this high linear energy transfer (high-LET) radiation is not dependent on active cell proliferation or oxygenation, and the resulting DNA damage caused by $\alpha$-particles is much more difficult to repair than that of $\beta^{-}$. Thus, highly cytotoxic radiation directed to the relevant tumor cell deposits holds the promise of adding substantially to hitherto failing curative adjuvant chemotherapy both when administered intraperitoneally (i.p.) for ovarian cancer, and as a systemic curative adjuvant treatment for breast, colon, prostate, and other malignancies, constituting a "systemic conformal radiotherapy at the cellular level."
Monoclonal antibodies are so far the most commonly used vector $(1,2)$. Other targeting agents include substrate analogs, normally in the form of peptides $(3,4)$, or ligands like folic acid (5). The $\mathrm{mAb}$ can be the whole immunoglobulin molecule or fragments like $\mathrm{F}\left(\mathrm{ab}^{\prime}\right)_{2}$ or single chain, diabodies, etc. Clearance and tumor uptake vary with size and pharmacokinetic properties, and mAb can now even be tailor-made (6).

A brief introduction to the relatively small number of early stage clinical studies using TAT in a variety of situations will follow, i.e., in recurrent brain tumor (7-9), recurrent ovarian cancer (10), human epidermal growth factor receptor-2 (HER-2) positive i.p. cancers (11), myelogenous leukemia (12-16), nonHodgkin lymphoma (17), and metastatic melanoma $(18,19)$. There is also one randomized placebo-controlled trial using ${ }^{223} \mathrm{Ra}-$ dichloride (having a high affinity for bone tissue) for symptomatic skeletal metastases in prostate cancer, the use of which is now approved by the US Food and Drug Administration (FDA) (20).

\section{HOW COULD TAT BE INTEGRATED IN THE CLINIC?}

Today, the multimodal therapeutic approach often includes local gross-tumor eradication by surgery or external radiotherapy, together with or followed by regional adjuvant radiotherapy, and eventually systemic adjuvant chemotherapy. The order of these interventions may differ. As outlined, TAT is mainly aimed at microscopic residual disease and is therefore perhaps best used after adjuvant chemotherapy, but the timing and situation can vary. A number of thematic situations where TAT has, or may, 


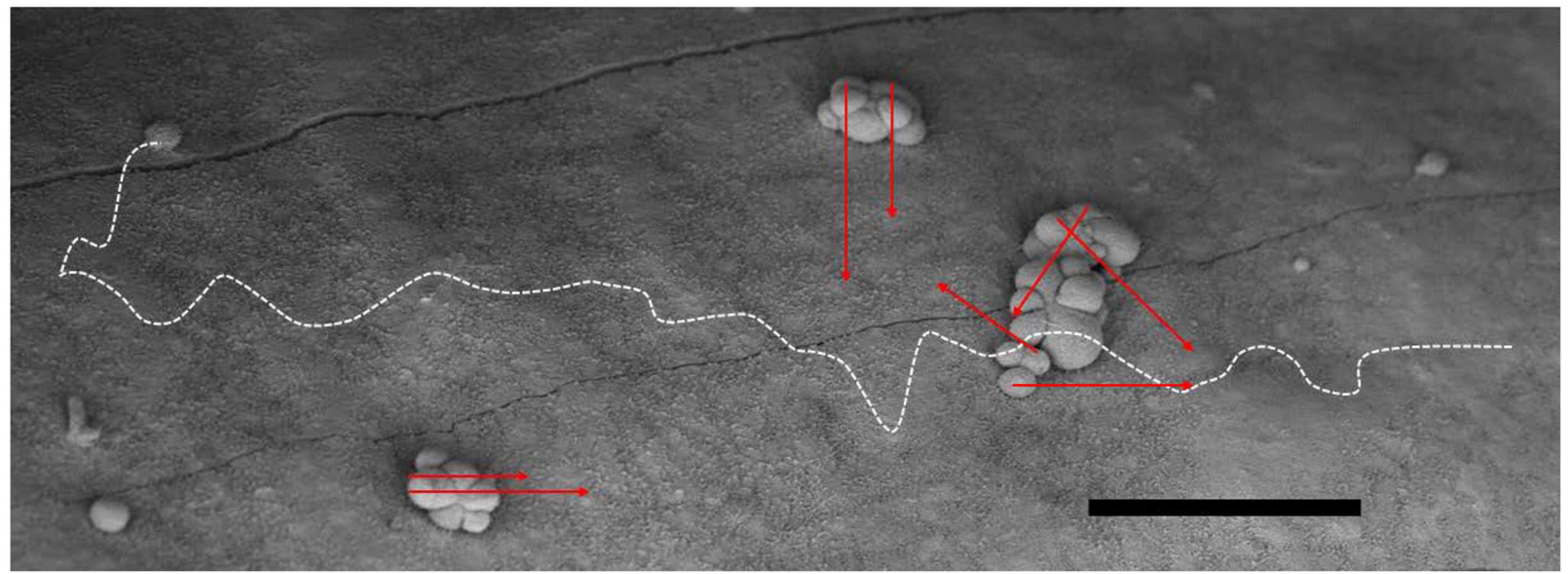

FIGURE 1 | The favorable geometric situation for $\alpha$-particles in small-scale metastases (e.g., in the adjuvant setting) is depicted in a scanning electron microscopy micrograph of micro-metastatic clusters from ovarian cancer on the peritoneal lining (mouse). The range of the $\alpha$-particles in red (here $\sim 50-70 \mu \mathrm{m}$ ), can hardly reach the surrounding normal healthy cells other than possibly the mesothelium and its sub-layer. They cannot reach the epithelial cells of the intestinal lining. The situation for $\beta^{-}$particles on the other hand, shows that a great deal of its energy will be deposited far away from the binding site and possibly into healthy tissue as demonstrated by the white dashed line (here $\sim 700 \mu \mathrm{m}$ ). Consequently, it may add to side effects. Bar equals $100 \mu \mathrm{m}$. be used are shortly discussed, relating both to the route of administration and/or a specific intention.

Intra-cavity administration is a natural starting point for the introduction of TAT in humans. By this approach, the risk of general side effects of critical organs, e.g., bone marrow, is minimized. Similarly, it reduces the risk of unknown toxicity due to unforeseen microscopic accumulation of the radioimmunocomplex elsewhere in the body. This relates to the use of $\alpha$-particle emitters with relatively short half-life, such as ${ }^{213} \mathrm{Bi}(\sim 45 \mathrm{~min})$ and ${ }^{211}$ At $(\sim 7.2 \mathrm{~h})$, because most of the radioactive decay will occur within the specific cavity before the substance is distributed throughout the body via the systemic and lymphatic systems. Indeed, this has been proved in recurrent malignant gliomas and for i.p. treatment of ovarian cancer (9-11). In tumor resection cavities, the anti-tenascin mAb ${ }^{211}$ At-81C6 was administered to 18 patients with recurrent brain tumors with no grade 3 or higher toxicity, and it was concluded to be a safe treatment with some positive effects (9). With equally low toxicity, the small 11-amino acid peptide substance $P$ (targeting the neurokinin type-1 receptor) conjugated to ${ }^{213} \mathrm{Bi}$ has been either injected in residual tumor or in the resection cavity of glioblastoma multiforme $(7,8)$.

The i.p. route of administration was used in nine patients with recurrent ovarian carcinoma using ${ }^{211}$ At-MX35, an antibody against sodium-dependent phosphate transport protein $2 \mathrm{~b}$ (NaP $\left.{ }_{i} 2 b\right)$ (10). The toxicity was mild, grade I-II, and specifically, there was no bone marrow toxicity. This was likely related to the fact that only $6 \%$ of injected initial activity concentration of the infused solution could be measured in serum, which peaked at $45 \mathrm{~h}$. Additionally, ${ }^{212} \mathrm{~Pb}$ conjugated to trastuzumab, an anti-HER2/neu receptor, for patients with HER-2 positive i.p. cancer has corroborated a low systemic distribution (11).

Adjuvant treatment for large tumor groups, e.g., breast, colorectal, and lung cancer, today includes systemically delivered chemotherapy. Although there is a clear effect on survival, in the case of colon cancer, at most, about $30 \%$ of patients harboring micrometastases are cured (21). Similarly low, or lower, figures for the total efficacy of adjuvant chemotherapy apply for breast and other adjuvant therapies. It is thought that TAT could be suitable for a boost, or consolidating, therapy after primary surgery and adjuvant chemotherapy. Besides the more common epithelial cancer where adjuvant chemotherapy is used, it has been suggested that malignant melanoma might benefit from adjuvant TAT. ${ }^{213} \mathrm{Bi}-9.2 .27$, an antibody against human neural/glial antigen 2 (NG2), has been administered both intralesionally and i.v. in patients with metastatic melanoma with promising results $(18,19)$. The adjuvant situation is also the goal in ovarian cancer, with the benefit of using local i.p. administration (10). In future clinical trials, however, patients who would remain disease-free even without such an adjuvant therapy might be included. It will therefore be important to include stochastic and long-term risk assessments, such as secondary cancers and/or specific organ dysfunctions, in the therapy justification. In these cases, the equivalent absorbed doses in all relevant organs should be calculated, including a conservative estimate of the relative biological effectiveness (RBE) for the emitted $\alpha$-particles (22).

If tumor dissemination is confined to the peritoneum today, extensive cytoreductive surgery with i.p. chemotherapy is suggested for selected patients, and i.p. TAT may be used as an additional boost therapy. An analogous local adjuvant treatment situation would be after surgery for peritoneal or pleural mesothelioma. Other multiple special-case scenarios include, e.g., optimized treatment of neuroendocrine tumors expressing somatostatin receptors, using the synthetic ligand octreotate (23), which today are treated with $\beta^{-}$-particles such as ${ }^{177} \mathrm{Lu}$, if kidney toxicity could be shown to be less. In the diffuse-type gastric cancer 
subset, TAT using, e.g., a mutated E-cadherin mAb may represent an option for treatment (24).

Palliative treatment can be envisaged for relief of specific symptoms from localized disease using the intra-cavity route of administration like meningeal, pleural, or peritoneal carcinomatosis; the latter is currently being explored (11). Prolongation of life was found with i.v. injected ${ }^{223} \mathrm{Ra}$-dicloride (Xofigo ${ }^{\circledR}$, formerly named Alpharadin) in a placebo-controlled phase III trial for castration-resistant prostate cancer metastases (20). Although ${ }^{223} \mathrm{Ra}$-dicloride is not conjugated to a targeting molecule, it can be considered as targeted on the basis of its affinity for bone tissue, due to similarities to calcium. The other study objectives, to give symptom relief of bone metastasis and reduce skeletal events, were also fulfilled. Hematological toxicity was surprisingly low and a good tolerability is truly important in palliative treatment. This drug is now also investigated for retreatment (25) and use in combination treatment with docetaxel (26) and also in osteosarcoma (27). A true targeted therapy (i.e., a radionuclide bound to a tumor-specific agent) in early stage prostate cancer, with only minimal metastatic disease, could be used before the appearance of bone metastasis-related symptoms. At the time when only the prostate specific antigen (PSA) level has started to increase, after optimal local and endocrine treatment, as a possible adjunct PSA salvage treatment.

Systemically dispersed myelo-lymphoproliferative malignancies are more rapidly accessible for radioconjugate binding compared with solid tumors, when considered as floating cell suspensions. However, they do form extensive aggregates in the bone marrow and in peripheral lymphoid tissues. RIT with the longer range, low energy $\beta^{-}$-particle-emitting conjugates (Zevalin ${ }^{\circledR} /$ Bexxar $^{\circledR}$ ) is useful for the more bulky lymphomas and are approved for follicular B-cell non-Hodgkin lymphoma, but comes with long-lasting bone marrow toxicity (28). The safety and feasibility of TAT with ${ }^{213} \mathrm{Bi}$ lintuzumab (HuM195), a humanized anti-CD33 mAb that targets myeloid leukemia cells, has been established $(12,14)$. Importantly, anti-leukemic effects were also demonstrated, providing the first proof-of-concept in human (12). It is suggested that when introducing TAT directly after chemotherapy, the cytoreductive effect of the chemotherapy can enhance the possibility of a saturation of CD33 sites by the targeted drug, which will increase the number of radionuclides delivered to leukemia cells without the need for activity escalation (13). To even further enhance the effects, the same $\mathrm{mAb}$ is now being conjugated to the in vivo $\alpha$-particle generator ${ }^{225} \mathrm{Ac}$, which decays in a serie emitting four $\alpha$-particles (15), see Figure 2. Additionally, an on-going investigation is using the combination of ${ }^{225}$ Ac-lintuzumab and the cytotoxic drug cytarabine in older patients with acute myeloid leukemia (AML) (16). The surface targets used today are mostly present to a certain degree on normal hematological cells. Therefore, bone marrow toxicity is of concern and more malignant cell-specific targets are warranted.

Regarding manifest macroscopic disease, as has been argued, this situation might not be theoretically optimal for TAT. However, there are some clinical indications that TAT may actually be of use also for treating macroscopic tumors. Firstly, there is an interesting phase I trial for manifest stage IV malignant melanoma with promising results, including an objective partial response

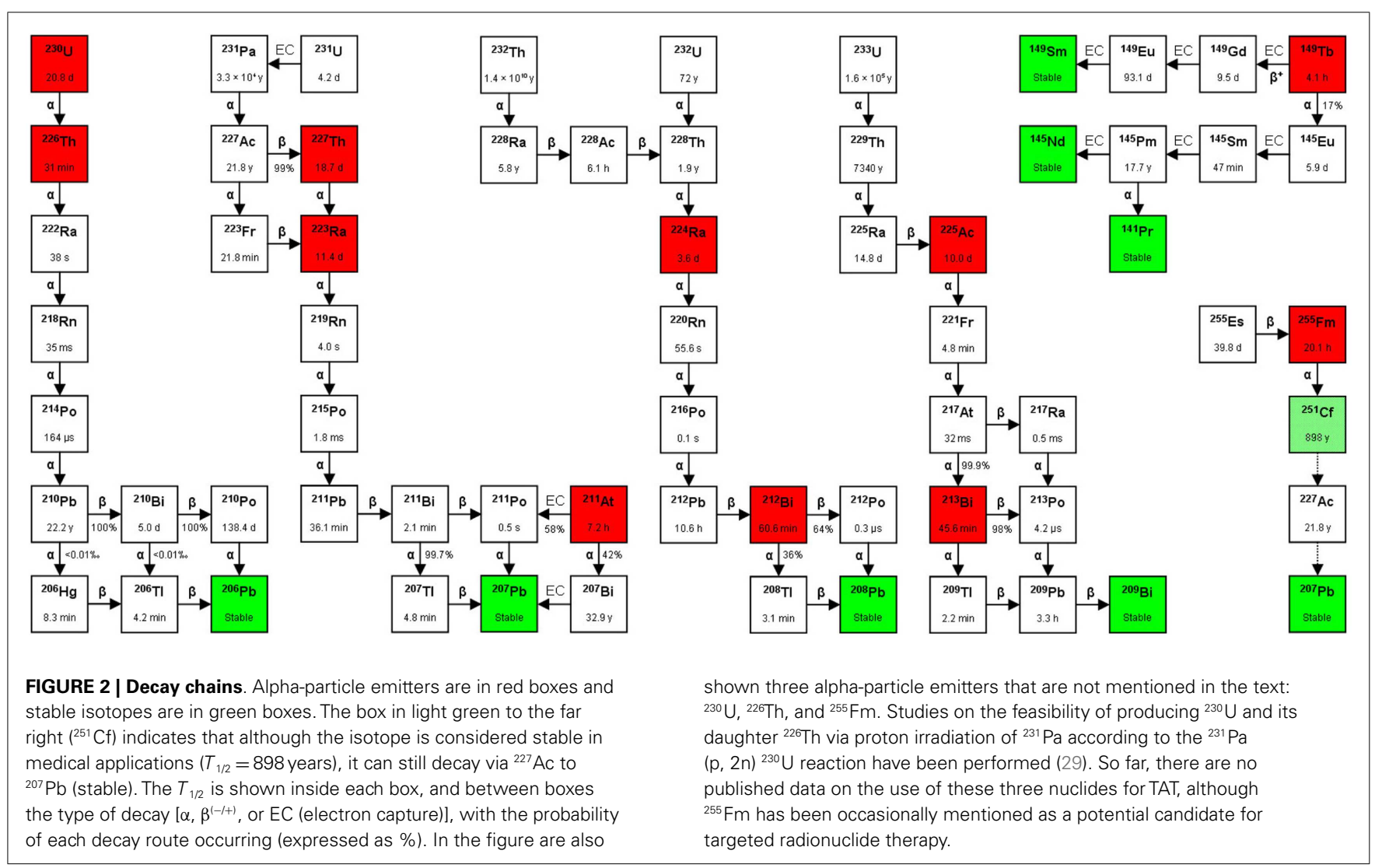


rate of 10 and $40 \%$ of patients having stable disease at 8 weeks (19). A total of 38 patients were treated with the 9.2.27 $\mathrm{mAb}$ (against human melanoma chondroitin sulfate proteoglycan) conjugated to ${ }^{213} \mathrm{Bi}$. Secondly, preliminary reports of a phase I dose escalation trial with ${ }^{213} \mathrm{Bi}$-labeled anti-CD20 against relapsed or refractory non-Hodgkin lymphoma preliminary showed no acute or extramedullary toxicity in two responders out of nine treated patients (17). These results are even more promising considering the short half-life of ${ }^{213} \mathrm{Bi}(\sim 45 \mathrm{~min})$, since a more long-lived nuclide would likely have been able to penetrate the tumor masses better, with possibly even better therapeutic effects. Thus, it is argued that if penetration is optimized and high enough activity is delivered to yield homogenous curative doses, also tumors in the size range of 5-10 $\mathrm{mm}$ can be eradicated, as has been shown experimentally (30). This potential could even be further enhanced with the use of pre-targeting strategies (see separate section).

\section{THE OVARIAN CANCER EXAMPLE}

The ovarian cancer example aims to use RIT as a locally injected adjuvant therapy. Unfortunately, epithelial ovarian cancer (EOC) mortality has not decreased during the last decades, despite a decline in incidence and treatment intensification. Diagnosis is commonly made at an advanced stage with widespread peritoneal dissemination; $70-75 \%$ of the patients are diagnosed at more advanced stages i.e., > stage I. Standard therapy for stage II and higher constitutes surgery with cytoreductive intent (i.e., removal of as much as possible of the macroscopic tumors from the peritoneal surface including bilateral salpingo-oophorectomy), supplemented by i.v. chemotherapy, and sometimes i.p. chemotherapy (31). To enhance survival, trials have assessed the use of whole abdominal or moving-strip external-beam radiotherapy (EBRT) (32), or non-specific i.p. radiotherapy with colloid preparations of ${ }^{198} \mathrm{Au}$ or ${ }^{32} \mathrm{P}$ as adjuvant therapies $(33,34)$. However, the results of these studies have not justified their routine use and long-term toxicity in normal tissues is a major concern. However, even when cytoreductive surgery and chemotherapy result in complete remission at second-look laparotomy and normalization of the serum marker cancer antigen 125 (CA-125), about $70 \%$ of patients with stage III ovarian cancer will relapse. Recurrence is often characterized by gradual development of ascites and chemotherapy-resistant tumor cells, growing as peritoneal microscopic cell deposits, eventually leading to intestinal adhesions and bowel obstruction.

Chemotherapy injected i.p. in the abdominal cavity can result in both a reduction in recurrences and a decrease in mortality, although at the cost of increased normal tissue toxicity (35, 36). The advantage of i.p. administration compared with i.v. injection for localizing radiolabeled $\mathrm{mAb}$ to microscopic peritoneal tumor disease was shown in earlier studies, both in animal models and in patients $(37,38)$. Therefore, local treatment with the $\beta^{-}$-particle-emitting radioconjugate ${ }^{90} \mathrm{Y}-\mathrm{HFMG}$ (human milk fat globule-1, a mAb toward MUC-1) was investigated in a large randomized controlled phase III trial, but overall survival did not improve, although a slight decrease in local intraperitoneal recurrence was observed $(39,40)$. This negative result might be in part explained by the delivery of a too low absorbed dose from the emitted $\beta^{-}$-particles to single tumor cells or micrometastases. Consequently, i.p. TAT using specific mAb labeled with $\alpha$-particle-emitting radionuclides, with the higher LET and shorter path length than $\beta^{-}$-particles, could be more effective. A phase I study has used the mAb MX35 $\mathrm{F}\left(\mathrm{ab}^{\prime}\right)_{2}$ fragments labeled with ${ }^{211} \mathrm{At}$, that was administered as i.p. infusion to patients with relapsed ovarian cancer but after having achieved a complete macroscopic response on second-line chemotherapy (10). The tolerability was very good and it was concluded that this treatment could achieve therapeutic absorbed doses in microscopic tumor nodules without causing any radiation-related toxicity (10).

\section{RADIONUCLIDES}

Some important physical characteristics of relevant $\alpha$-particle emitters are presented below, with reference to studies on their therapeutic applications. See Figure 2 for a schematic of the different decay pathways. Importantly, as it is not possible to directly measure the $\alpha$ decay in vivo, even a small amount of accompanying $\gamma$-radiation will enable scintigraphic evaluation for pharmacokinetic and dosimetric studies to be performed. All $\alpha$-particle emitters with a serial decay that includes $\alpha$-particle daughters can present problems, as the daughters will detach from the targeting vector due to the elevated recoil energy (up to $200 \mathrm{keV}$ ). Such free nuclides can then diffuse away, leading to untargeted irradiation of normal tissues. Using microdosimetry, the energy deposited in the target could be reduced by $50 \%$, as has been calculated for the ${ }^{211}$ At $\alpha$-particle-emitting daughter ${ }^{210} \mathrm{Po}$, with a $T_{1 / 2}$ of $0.5 \mathrm{~s}$ (41). Actinium-225 $\left({ }^{225} A c\right)$ has a $T_{1 / 2}$ of 10 days, causing the emission of four $\alpha$-particles in a serial decay. The decay is accompanied by $\gamma$-radiation. This nuclide can have great therapeutic potential when radiochemistry can produce stable binding to ${ }^{225} \mathrm{Ac}$ and its daughters. This nuclide is available as a consequence of producing ${ }^{233} \mathrm{U}$ via the nuclear reaction ${ }^{232} \mathrm{Th}(\mathrm{n}, \gamma){ }^{233} \mathrm{Th}\left(\beta^{-}\right){ }^{233} \mathrm{~Pa}\left(\beta^{-}\right)$ ${ }^{233} \mathrm{U}$ for nuclear energy and nuclear weapons purposes decades ago (Figure 2). The possibility of producing ${ }^{225}$ Ac by use of a cyclotron via the ${ }^{226} \mathrm{Ra}(\mathrm{p}, 2 \mathrm{n}){ }^{225} \mathrm{Ac}$ is now also investigated (42). ${ }^{225} \mathrm{Ac}$ is currently tested in two clinical studies where it is conjugated to the anti-CD33 mAb HuM195 $(15,16)$.

Radium-223 $\left({ }^{223} \mathrm{Ra}\right)$ has a $T_{1 / 2}$ of 11.4 days and emits four $\alpha$ - and two $\beta^{-}$-particles in the decay chain as well as $\gamma$-rays, until the stable isotope ${ }^{207} \mathrm{~Pb}$ is obtained. This nuclide can be produced by neutron activation of ${ }^{226} \mathrm{Ra}$ by the nuclear reaction ${ }^{226} \mathrm{Ra}(\mathrm{n}, \gamma){ }^{227} \mathrm{Ra}\left(\beta^{-}\right){ }^{227} \mathrm{Ac}$ (Figure 2). ${ }^{223} \mathrm{Ra}$ is an alkaline earth metal ion and similarly to calcium ions, it accumulates in the bone. To this aim, ${ }^{223} \mathrm{Ra}$-dichloride was developed and is now FDA-approved for bone metastases in castration-resistant prostate cancer (20).

Bismuth-213 $\left({ }^{213} \mathrm{Bi}\right)$ decays with a $T_{1 / 2}$ of $45.6 \mathrm{~min}$ to ${ }^{209} \mathrm{Bi}$ (stable), during which it emits one $\alpha$-particle and an accompanied $440 \mathrm{keV} \gamma$-radiation. This nuclide can be obtained by elution of the ${ }^{225} \mathrm{Ac} /{ }^{213} \mathrm{Bi}$ generator, thereby making availability and dispersion to clinical centers possible. The generator is produced by the Oak Ridge National Laboratory in the USA and by the Institute for Transuranium Elements in Karlsruhe, Europe. Although the drawback of its short half-time puts high demand on the logistics for radiochemistry and treatment, ${ }^{213} \mathrm{Bi}$ has still been the most used TAT nuclide in clinical trials so far (12-14, 17-19). 
Bismuth-212 $\left({ }^{212} \mathrm{Bi}\right)$ has a $T_{1 / 2}$ of $60.6 \mathrm{~min}$ and emits one $\alpha$ and one $\beta^{-}$-particle. High energy $(2.6 \mathrm{MeV}) \gamma$-rays are emitted in the decay; therefore, patients must be treated using special radiation protection routines. This nuclide is available as a consequence of producing ${ }^{233} \mathrm{U}$ via the nuclear reaction ${ }^{232} \mathrm{Th}(\mathrm{n}, \gamma)$ ${ }^{233} \mathrm{Th}\left(\beta^{-}\right){ }^{233} \mathrm{~Pa}\left(\beta^{-}\right){ }^{233} \mathrm{U}(\mathrm{n}, 2 \mathrm{n}){ }^{232} \mathrm{U}$ for nuclear energy and nuclear weapon purposes decades ago (Figure 2). The last step in which ${ }^{232} \mathrm{U}$ was produced via the $(\mathrm{n}, 2 \mathrm{n})$ reaction was an unwanted side reaction during the production of ${ }^{233} \mathrm{U}$ (Figure 2). However, the parent nuclide of ${ }^{212} \mathrm{Bi}$ is the $\beta^{-}$-emitter ${ }^{212} \mathrm{~Pb}$, having a $T_{1 / 2}$ of $10.6 \mathrm{~h}$. The chelator TCMC is used with ${ }^{212} \mathrm{~Pb}$ and functions as an in vivo nanogenerator for the $\alpha$-particle emitter ${ }^{212} \mathrm{Bi}$. The University of Alabama (USA) has started a clinical trial to evaluate ${ }^{212} \mathrm{~Pb}$-TCMC-trastuzumab toxicity levels and anti-tumor efficacy in patients with HER-2 positive cancers in the abdominal cavity (11).

Astatine-211 $\left({ }^{211} A t\right)$ decays with a $T_{1 / 2}$ of $7.2 \mathrm{~h}$ and emits an $\alpha$-particle in both of the two possible decay routs to the stable nuclide ${ }^{207} \mathrm{Bi}$. Scintigraphy and standard dosimetry are possible due to the accompanying $\gamma$-radiation. The limited availability is currently a main obstacle for a wider use of this nuclide, as it can only be cyclotron produced (43). It has been used in clinical trials, locally administered in surgical resection cavities and i.p. as previously discussed $(9,10)$.

\section{DOSIMETRY}

Dosimetry was originally developed for radiation protection (44) and diagnostic imaging (45), but is now also needed for optimization of the therapeutic situation using radiopharmaceuticals. The basic concepts of dosimetry are presented in two Medical Internal Radiation Dose (MIRD) publications $(46,47)$.

$\alpha$-Particle dosimetry takes into account a number of different parameters, particularly the short path length of $\alpha$-particles in tissue $(\sim 100 \mu \mathrm{m})$ and the inhomogeneous distribution of $\alpha$ radiopharmaceuticals in tumors and tissues. Thus, predicting the biological effect based on mean absorbed dose in a tumor or organ might be misleading in some circumstances. The high-LET $(\sim 100 \mathrm{keV} / \mu \mathrm{m})$ and varying LET (with a maximum at the Bragg peak) along the $\alpha$-particle track are also parameters that have to be taken into account when performing $\alpha$-particle dosimetry.

The RBE of $\alpha$-particles ranges from 3 to 7, i.e., $\alpha$-particle irradiation is 3-7 times more therapeutically effective, or toxic, per unit of absorbed dose than photons or electrons (47). In TAT clinical studies, an RBE of five has been applied to estimate the equivalent absorbed doses $(10,14,48)$. The weighting factor applied when estimating the effective (or equivalent) absorbed dose (expressed in Sv, Sievert) is related to the stochastic effects of radiation, e.g., cancer induction. A factor of 20 is commonly recommended for the stochastic effects of $\alpha$-particles that should however not be used when predicting the therapeutic efficacy or toxicity in patients who receive TAT treatment. Indeed, this weighting factor was conservatively derived for radiation protection and was never meant for estimating the deterministic effects relevant to therapy (47). Also, the clinical experience with $\alpha$-particles is sparse, and therefore the tolerance to absorbed doses in humans has yet to be determined.

$\alpha$-Particle dosimetry in the clinic require pharmacokinetic data similar to those that are required for conventional $\beta^{-}$-particle therapies (22), e.g., urine, blood, and peritoneal fluids in the case of i.p. treatment (10). All $\alpha$-particle emitters used so far in clinical studies $\left({ }^{211} \mathrm{At},{ }^{213} \mathrm{Bi},{ }^{223} \mathrm{Ra},{ }^{212} \mathrm{Bi}\right.$, and $\left.{ }^{225} \mathrm{Ac}\right)$ emit $\gamma$ photons, characteristic $\mathrm{X}$-ray, or bremsstrahlung radiation. Using the $\gamma$-camera makes quantification of biodistribution possible. The spatial resolution of such images is, however, fairly low. Also, the injected activity is much lower than in a diagnostic setting, generally resulting in a poor signal-to-noise ratio. For similar reasons, 3-Dimensional single-photon emission computerized tomography (SPECT) imaging of the activity distribution in patients is time-consuming. The accuracy could be increased using co-registration techniques with computed tomography (CT) images (49).

Obviously, the absorbed dose in tumors and normal tissues need to be estimated from preclinical studies before initiating treatment studies. However, clinical quantification with the $\gamma$ camera can only give an estimate of the uptake of the radiopharmaceutical in whole organs and in macroscopic tumors, while quantification of the absorbed dose in smaller compartments in organs or microscopic tumors is hardly achievable. In TAT, the targeted tumors are often too small to be detected and, at best, indirect methods can be used for estimating the absorbed dose.

With regard to normal tissue protection, in certain cases, blocking agents can be used. For example, both astatine and iodine belong to the halogen elements and pre-treatment with potassium perchlorate can effectively prevent uptake of free ${ }^{211}$ At in cells expressing the sodium-iodine symporter (NIS), e.g., in the thyroid (10).

In the case of i.p. TAT for ovarian cancer, a control $\gamma$-camera image of the abdominal region with a radioactive-tracer analog to assure free distribution of the fluids is important. The radioactive flow out of the abdominal cavity can also be determined using a radioactive-tracer analog, by monitoring the activity concentration in blood over time (10). Pharmacokinetic data show that the variation in the absorbed dose in bone marrow can be around $20 \%$ (10). If the bone marrow is the dose-limiting organ, its absorbed dose then determines the maximal tolerated activity (MTA), and a radioactive-tracer analog study will be crucial for estimating the patient-specific MTA. However, for i.p. TAT, no effect on the hematopoiesis was recorded (10). Instead, other organs might determine the MTA, possibly the peritoneum; therefore, the activity concentration in the peritoneal fluid is crucial to calculate.

$\alpha$-Particle dosimetry on the cell level should be used when macrodosimetry cannot explain the results of an experiment or when it adds value to the macrodosimetric method (50). For $\alpha$ particles, the biological effect of just a single ionization event could be so large that the calculation of the mean absorbed dose in a tumor as a whole can be very misleading.

Hence, there is a need for microdosimetry when the statistical variation of the deposited radiation is not minimal in the target such as a cancer cell nucleus. The conceptual framework of microdosimetry that takes into account the stochastic nature of energy deposits in small microscopic targets was proposed almost 60 years ago (51), and the International Commission on Radiation Units and Measurements (ICRU) report No. 36 from 1983 defined all the microdosimetric concepts. Calculations and experiments have 
shown that as few as five high-LET $\alpha$-particle traversals through the cell nucleus are enough to kill a cell, whereas 10,000-20,000 low-LET $\beta^{-}$-particles are needed to achieve the same biological effect (52-54).

Importantly, microdosimetry should be considered for nontargeted but critical tissues, even if it receives a very low mean absorbed dose (47).

\section{THE BIOLOGY IN TARGETED $\alpha$ THERAPY}

The way high-LET radiation like $\alpha$-particles interact with biological matter has been described earlier $(53,55-60)$. They produce dense ionizations along a linear track and generate locally multiple damage sites in sensitive targets like DNA. These lesions, produced in close proximity to each other, are poorly repairable, thus making $\alpha$-particles highly deleterious $(61,62)$. While conventional EBRT is characterized by high absorbed doses delivered in a very short time in a homogenous way, TAT and radionuclide therapy in general are characterized by a low absorbed dose rate, protracted exposure, and heterogeneous energy deposit (63).

In EBRT, physical events predominate in the final outcome of the therapy, and most of the effects can be correlated to the absorbed dose according to a linear, linear-quadratic, or sigmoid relationship. Conversely, physical characteristics of targeted radionuclide therapy can offer the cells the opportunity to repair some of their sublethal lesions (64-67). Nuclear DNA plays a central role in response to targeted radionuclide therapy, but other cellular sub-compartments including the mitochondria and cell membrane might also be strongly involved in situations of heterogeneous energy deposits (68-74). Therefore, the biology of the irradiated tissue and its interaction with its environment might play an even more pronounced role in targeted radionuclide therapy than EBRT, and bystander and abscopal effects involving activation of signaling pathways and the immune system should probably be investigated more accurately (75-77). The consequences are that the absorbed dose-effect might be more difficult to establish and radiation-induced biological effects might be observed in tissues far beyond the physical path length of the $\alpha$-particles.

\section{PRE-TARGETED $\alpha$ THERAPY}

All targeted therapies rely on the ability of the vector to find its target and to allow the associated cytotoxic agent to deliver the cellkilling effect. Advances in genetic engineering have led to the development of many molecules that can be radiolabeled and used for RIT. However, despite the growing number of designed antibody fragments and fusion proteins, treatments are often hampered by less than optimal pharmacokinetics. The key lies in finding a balance between tumor radiation uptake and removal of circulating radioactivity. Rapid clearance of unbound radioimmunoconjugates is essential for limiting the absorbed dose to normal organs, but a too short a retention time in blood will result in a too short targeting time, and thus in the delivery of a too low absorbed dose to malignant cells.

This pharmacokinetic challenge can be handled by separating physically and temporally the targeting phase from the delivery of the ionizing radiation, an approach generally referred to as pre-targeted radioimmunotherapy (PRIT) $(78,79)$. A number of
PRIT regimens, all based on the same essential principle, have been proposed since the pre-targeting concept was proposed by Goodwin et al. in 1988 (80). In the first step, a targeting immunoconjugate (pre-targeting molecule) is administered and sufficient time is allowed for its localization at tumor-associated antigen sites. As the pre-targeting molecule does not carry any cytotoxic substance, normal tissues are not affected by lengthy circulation times during the distribution phase. Then, unbound immunoconjugate molecules can be removed from the circulation using a clearing agent, before injecting the radiolabeled vector (effector molecule). The effector molecule is a small molecule designed to rapidly diffuse into tumors and cancer cell clusters, where it will specifically bind to the antigen-associated pretargeting molecules. The fast clearance of unbound effector molecules improves the tumor-to-normal tissue ratios of absorbed dose compared with directly labeled immunoconjugates. With pre-targeting, no trade-off needs to be made between efficient targeting/penetration/tumor residence time and protection of dose-limiting normal tissues.

Efficient interaction between the pre-targeting molecule and the effector molecule has been achieved using a handful of techniques, particularly those based on streptavidin-biotin (81) or bispecific antibodies (82). Of the radionuclides with potential use in TAT, some appear more suitable than others when factors such as availability and daughter nuclides are taken into account, in addition to chelation and conjugation chemistry. In particular, two promising candidates for efficient therapy emerge: ${ }^{211}$ At and ${ }^{213} \mathrm{Bi}$. However, they both have short $T_{1 / 2}(7.2 \mathrm{~h}$ and $45.6 \mathrm{~min}$, respectively), which put high demands on the distribution of radiolabeled vectors to ensure favorable absorbed dose ratios. This issue could be overcome by using a pre-targeting strategy, thereby increasing the therapeutic potential of these short-lived $\alpha$-particle emitters.

Several preclinical studies have shown the benefits of pretargeted $\alpha$ therapy (PTAT), mainly in hematological cancers, such as AML (83), non-Hodgkin lymphoma (84), anaplastic large cell lymphoma (85), and adult T-cell leukemia (85). PTAT for disseminated ovarian carcinoma was evaluated in one study in which ${ }^{211}$ At-PRIT (1.5 MBq) and ${ }^{211}$ At-RIT (0.9 MBq) were compared in a mouse model of i.p. TAT (86). The administered activities were based on the previously estimated MTAs for the two regimens and resulted in equal tumor-free fractions (TFF; 0.45) 8 weeks after irradiation; however, the mice treated with ${ }^{211}$ At-PRIT had smaller tumors and lower ascites incidence. This indicates that pre-targeting can improve the outcome also of i.p. TAT, although the greatest gain of PTAT is generally considered to be in systemic treatments.

\section{SUMMARY AND FUTURE PERSPECTIVES}

Radioimmunotherapy with short-ranged, high-efficiency $\alpha$ particles is a very attractive and promising treatment strategy. $\alpha$-Particles have an advantage in targeted therapy because of their exceptionally high cell-killing ability. Therefore, different from RIT with $\beta^{-}$-particles, $\alpha$-particle emitters labeled to a targeting vector can directly kill single cancer cells (by self-irradiation). Several completed or on-going clinical trials using TAT have shown its feasibility for treating disseminated and/or micro-metastatic 
malignancies without significant or insurmountable problems of toxicity. Although the definition of micrometastases is vague, in clinical oncology occult metastases (i.e., not detected by routinely used imaging procedures) might involve single tumor cells up to clusters of billions of cells. Therefore, a cocktail of both $\alpha$ - and $\beta^{-}$emitting radioconjugates might be more effective in some cases.

The possibility of TAT as a potential curative treatment includes its use as a local boost after initial treatment (e.g., i.p. in EOC), or perhaps as i.v. systemic adjuvant treatment, both targeting micro-metastatic disease. A systemic approach may indeed be of particular interest in patients with EOC that includes retroperitoneal vascularized metastases, e.g., in the lymph nodes. Fractionated RIT is another potentially interesting regimen to improve the therapeutic index, thus resulting in reduced normal organ toxicity while maintaining the therapeutic efficacy (87). Radionuclides that emit Auger electrons could offer an alternative approach compared with the nuclides described in this article, reviewed elsewhere (88). Auger electrons are energetically very weak $(<<1 \mathrm{keV})$ and have a path length in tissue that is far shorter than that of $\alpha$-particles. However, to effectively damage DNA molecules, the Auger emitter has to bind to the DNA.

The therapeutic outcome of TAT is influenced by a number of crucial issues that all need to be handled, e.g., the specificity of the antibody/targeting construct; the level of antigenic expression on the tumor cells; the potential loss of immunoreactivity of the antibody/targeting construct; the amount of unlabeled antibody/targeting construct after injection; the existence of diffusion barriers that hinder the penetration of the antibody/targeting construct into the tumors; the choice of radionuclide (half-life and path length); too low specific radioactivity; and for the i.p. situation, any extra peritoneal location of tumor cells.

A major issue that may hamper wide implementation in the clinic and that needs to be simultaneously addressed is the availability of suitable $\alpha$-particle emitters at a reasonable cost $(43,89)$. Otherwise, TAT will remain just a potentially effective treatment, or a very rarely implemented option. Finally, after safety issues and pharmacokinetics have been established, for all types of malignancies that might benefit from TAT/PTAT, we need to conduct randomized, controlled, clinical studies. These need to include a high enough number of patients to allow meaningful comparison and evaluation of different treatment strategies.

\section{REFERENCES}

1. Olafsen T, Elgqvist J, Wu AM. Protein targeting constructs in alpha therapy. Curr Radiopharm (2011) 4(3):197-213. doi:10.2174/1874471011104030197

2. Sharkey RM, Goldenberg DM. Cancer radioimmunotherapy. Immunotherapy (2011) 3(3):349-70. doi:10.2217/imt.10.114

3. Dong C, Liu Z, Wang F. Peptide-based radiopharmaceuticals for targeted tumor therapy. Curr Med Chem (2013) 21(1):139-52.

4. Pool SE, Krenning EP, Koning GA, van Eijck CH, Teunissen JJ, Kam B, et al. Preclinical and clinical studies of peptide receptor radionuclide therapy. Semin Nucl Med (2010) 40(3):209-18. doi:10.1053/j.semnuclmed.2009.12.001

5. Muller C, Schibli R. Prospects in folate receptor-targeted radionuclide therapy. Front Oncol (2013) 3:249. doi:10.3389/fonc.2013.00249

6. Olafsen T, Kenanova VE, Wu AM. Tunable pharmacokinetics: modifying the in vivo half-life of antibodies by directed mutagenesis of the Fc fragment. Nat Protoc (2006) 1 (4):2048-60. doi:10.1038/nprot.2006.322

7. Cordier D, Forrer F, Bruchertseifer F, Morgenstern A, Apostolidis C, Good S, et al. Targeted alpha-radionuclide therapy of functionally critically located gliomas with 213Bi-DOTA-[Thi8,Met(O2)11]-substance P: a pilot trial. Eur J Nucl Med Mol Imaging (2010) 37(7):1335-44. doi:10.1007/s00259-010-1385-5

8. Kneifel S, Cordier D, Good S, Ionescu MC, Ghaffari A, Hofer S, et al. Local targeting of malignant gliomas by the diffusible peptidic vector $1,4,7,10$ tetraazacyclododecane-1-glutaric acid-4,7,10-triacetic acid-substance p. Clin Cancer Res (2006) 12(12):3843-50. doi:10.1158/1078-0432.CCR-05-2820

9. Zalutsky MR, Reardon DA, Akabani G, Coleman RE, Friedman AH, Friedman HS, et al. Clinical experience with alpha-particle emitting 211At: treatment of recurrent brain tumor patients with 211At-labeled chimeric antitenascin monoclonal antibody 81C6. J Nucl Med (2008) 49(1):30-8. doi:10.2967/jnumed.107. 046938

10. Andersson H, Cederkrantz E, Back T, Divgi C, Elgqvist J, Himmelman J, et al. Intraperitoneal alpha-particle radioimmunotherapy of ovarian cancer patients: pharmacokinetics and dosimetry of (211)At-MX35 F(ab')2 - a phase I study. J Nucl Med (2009) 50(7):1153-60. doi:10.2967/jnumed.109.062604

11. Meredith RF, Torgue J, Azure MT, Shen S, Saddekni S, Banaga E, et al. Pharmacokinetics and imaging of (212) Pb-TCMC-Trastuzumab after intraperitoneal administration in ovarian cancer patients. Cancer Biother Radiopharm (2014) 29(1):12-7. doi:10.1089/cbr.2013.1531

12. Jurcic JG, Larson SM, Sgouros G, McDevitt MR, Finn RD, Divgi CR, et al. Targeted alpha particle immunotherapy for myeloid leukemia. Blood (2002) 100(4):1233-9.

13. Rosenblat TL, McDevitt MR, Mulford DA, Pandit-Taskar N, Divgi CR, Panageas KS, et al. Sequential cytarabine and alpha-particle immunotherapy with bismuth-213-lintuzumab (HuM195) for acute myeloid leukemia. Clin Cancer Res (2010) 16(21):5303-11. doi:10.1158/1078-0432.ccr-10-0382

14. Sgouros G, Ballangrud AM, Jurcic JG, McDevitt MR, Humm JL, Erdi YE, et al. Pharmacokinetics and dosimetry of an alpha-particle emitter labeled antibody: 213Bi-HuM195 (anti-CD33) in patients with leukemia. J Nucl Med (1999) 40(11):1935-46.

15. Memorial Sloan Kettering Cancer C, National Cancer Institute, Actinium Pharmaceuticals. Targeted Atomic Nano-Generators (Actinium-225-Labeled Humanized Anti-CD33 Monoclonal Antibody HuM195) in Patients With Advanced Myeloid Malignancies. U.S. National Institutes of Health (2014).

16. M.D. Anderson Cancer Center, Actinium Pharmaceuticals. Low Dose Cytarabine and Lintuzumab-Ac225 in Older Patients. U.S. National Institutes of Health (2015).

17. Heeger S, Moldenhauer G, Egerer G, Wesch H, Martin S, Nikula T, et al., editors. Alpha radioimmunotherapy of B-lineage non-Hodgkin's lymphoma using 213Bi-labeled anti-CD19- and anti-CD20-CHX-A"-DTPA conjugates. Proceedings of the 225th ACS National Meeting, Division of Nuclear Chemistry \& Technology; 2003 March 23-27; New Orleans, LA, USA. (2003). Available from: http://oasys2.confex.com/acs/225nm/techprogram/P613172.HTM

18. Allen BJ, Raja C, Rizvi S, Li Y, Tsui W, Graham P, et al. Intralesional targeted alpha therapy for metastatic melanoma. Cancer Biol Ther (2005) 4(12):1318-24. doi:10.4161/cbt.4.12.2251

19. Allen BJ, Singla AA, Rizvi SM, Graham P, Bruchertseifer F, Apostolidis C, et al. Analysis of patient survival in a phase I trial of systemic targeted alpha-therapy for metastatic melanoma. Immunotherapy (2011) 3(9):1041-50. doi:10.2217/imt.11.97

20. Parker C, Nilsson S, Heinrich D, Helle SI, O'Sullivan JM, Fossa SD, et al. Alpha emitter radium-223 and survival in metastatic prostate cancer. $N$ Engl J Med (2013) 369(3):213-23. doi:10.1056/NEJMoa1213755

21. Glimelius B, Dahl O, Cedermark B, Jakobsen A, Bentzen SM, Starkhammar H, et al. Adjuvant chemotherapy in colorectal cancer: a joint analysis of randomised trials by the Nordic Gastrointestinal Tumour Adjuvant Therapy Group. Acta Oncol (2005) 44(8):904-12. doi:10.1080/02841860500355900

22. Palm S, Elgqvist J, Jacobsson L. Patient-specific alpha-particle dosimetry. Curr Radiopharm (2011) 4(4):329-35. doi:10.2174/1874471011104040329

23. Vaidyanathan G, Boskovitz A, Shankar S, Zalutsky MR. Radioiodine and 211Atlabeled guanidinomethyl halobenzoyl octreotate conjugates: potential peptide radiotherapeutics for somatostatin receptor-positive cancers. Peptides (2004) 25(12):2087-97. doi:10.1016/j.peptides.2004.08.018

24. Senekowitsch-Schmidtke R, Schuhmacher C, Becker KF, Nikula TK, Seidl C, Becker I, et al. Highly specific tumor binding of a 213Bi-labeled monoclonal antibody against mutant E-cadherin suggests its usefulness for locoregional alpha-radioimmunotherapy of diffuse-type gastric cancer. Cancer Res (2001) 61(7):2804-8. 
25. Bayer. Re-Treatment Safety of Radium-223 Dichloride in Castration-resistant Prostate Cancer With Bone Metastases. U.S. National Institutes of Health (2017).

26. Algeta ASA, Bayer. A Study of Alpharadin ${ }^{\circledR}$ With Docetaxel in Patients With Bone Metastasis From Castration-Resistant Prostate Cancer (CRPC). U.S. National Institutes of Health (2014).

27. M.D. Anderson Cancer Center, Bayer. Phase I Dose Escalation of Monthly Intravenous Ra-223 Dichloride in Osteosarcoma. U.S. National Institutes of Health (2016).

28. Bodet-Milin C, Ferrer L, Pallardy A, Eugene T, Rauscher A, Alain F-C, et al. Radioimmunotherapy of B-cell non-Hodgkin's lymphoma. Front Oncol (2013) 3:177. doi:10.3389/fonc.2013.00177

29. Morgenstern A, Lebeda O, Stursa J, Bruchertseifer F, Capote R, McGinley J, et al. Production of 230U/226Th for targeted alpha therapy via proton irradiation of 231Pa. Anal Chem (2008) 80(22):8763-70. doi:10.1021/ac801304c

30. Bäck T, Chouin N, Lindegren S, Jensen H, Palm S, Albertsson P. Tumor growth of subcutaneous xenografts after repeated alpha-radioimmunotherapy with astatine-211: what absorbed dose is required to treat solid tumors with alpha emitters? Eur J Nucl Med Mol Imaging (2012) 39(Suppl 2):S324.

31. Morgan RJ Jr, Alvarez RD, Armstrong DK, Chen LM, Copeland L, Fowler J, et al. Ovarian cancer. Clinical practice guidelines in oncology. J Natl Compr Canc Netw (2006) 4(9):912-39.

32. Einhorn N, Trope C, Ridderheim M, Boman K, Sorbe B, Cavallin-Stahl E. A systematic overview of radiation therapy effects in ovarian cancer. Acta Oncol (2003) 42(5-6):562-6. doi:10.1080/02841860310014426

33. Rosenshein NB, Leichner PK, Vogelsang G. Radiocolloids in the treatment of ovarian cancer. Obstet Gynecol Surv (1979) 34(9):708-20.

34. Varia MA, Stehman FB, Bundy BN, Benda JA, Clarke-Pearson DL, Alvarez RD, et al. Intraperitoneal radioactive phosphorus (32P) versus observation after negative second-look laparotomy for stage III ovarian carcinoma: a randomized trial of the Gynecologic Oncology Group. J Clin Oncol (2003) 21(15):2849-55. doi:10.1200/JCO.2003.11.018

35. Armstrong DK, Bundy B, Wenzel L, Huang HQ, Baergen R, Lele S, et al. Intraperitoneal cisplatin and paclitaxel in ovarian cancer. N Engl J Med (2006) 354(1):34-43. doi:10.1056/NEJMoa052985

36. Jaaback K, Johnson N, Lawrie TA. Intraperitoneal chemotherapy for the initial management of primary epithelial ovarian cancer. Cochrane Database Syst Rev (2011) 9(11):CD005340. doi:10.1002/14651858.CD005340.pub3

37. Andersson H, Elgqvist J, Horvath G, Hultborn R, Jacobsson L, Jensen H, et al. Astatine-211-labeled antibodies for treatment of disseminated ovarian cancer: an overview of results in an ovarian tumor model. Clin Cancer Res (2003) 9(10 Pt 2):3914S-21S.

38. Ward BG, Mather SJ, Hawkins LR, Crowther ME, Shepherd JH, Granowska $\mathrm{M}$, et al. Localization of radioiodine conjugated to the monoclonal antibody HMFG2 in human ovarian carcinoma: assessment of intravenous and intraperitoneal routes of administration. Cancer Res (1987) 47(17): 4719-23.

39. Oei AL, Verheijen RH, Seiden MV, Benigno BB, Lopes A, Soper JT, et al. Decreased intraperitoneal disease recurrence in epithelial ovarian cancer patients receiving intraperitoneal consolidation treatment with yttrium-90labeled murine HMFG1 without improvement in overall survival. Int J Cancer (2007) 120(12):2710-4. doi:10.1002/ijc.22663

40. Verheijen RH, Massuger LF, Benigno BB, Epenetos AA, Lopes A, Soper JT, et al. Phase III trial of intraperitoneal therapy with yttrium-90-labeled HMFG1 murine monoclonal antibody in patients with epithelial ovarian cancer after a surgically defined complete remission. J Clin Oncol (2006) 24(4):571-8. doi:10.1200/jco.2005.02.5973

41. Palm S, Humm JL, Rundqvist R, Jacobsson L. Microdosimetry of astatine211 single-cell irradiation: role of daughter polonium-211 diffusion. Med Phys (2004) 31(2):218-25. doi:10.1118/1.1640951

42. Apostolidis C, Molinet R, McGinley J, Abbas K, Mollenbeck J, Morgenstern A. Cyclotron production of Ac-225 for targeted alpha therapy. Appl Radiat Isot (2005) 62(3):383-7. doi:10.1016/j.apradiso.2004.06.013

43. Zalutsky MR, Pruszynski M. Astatine-211: production and availability. Curr Radiopharm (2011) 4(3):177-85. doi:10.2174/1874471011104030177

44. International Commission on Radiological Protection. Committee 4. Report of Committee IV on Evaluation of Radiation Doses to Body Tissues from International Contamination Due to Occupational Exposure. 1st ed. Oxford: Pergamon (1968). 94 p.
45. Loevinger R, Berman M. A formalism for calculation of absorbed dose from radionuclides. Phys Med Biol (1968) 13(2):205-17. doi:10.1088/0031-9155/13/ 2/306

46. Bolch WE, Eckerman KF, Sgouros G, Thomas SR. MIRD pamphlet no. 21: a generalized schema for radiopharmaceutical dosimetry - standardization of nomenclature. J Nucl Med (2009) 50(3):477-84. doi:10.2967/jnumed.108. 056036

47. Sgouros G, Roeske JC, McDevitt MR, Palm S, Allen BJ, Fisher DR, et al. MIRD pamphlet no. 22 (abridged): radiobiology and dosimetry of alpha-particle emitters for targeted radionuclide therapy. J Nucl Med (2010) 51(2):311-28. doi:10.2967/jnumed.108.058651

48. Bruland OS, Nilsson S, Fisher DR, Larsen RH. High-linear energy transfer irradiation targeted to skeletal metastases by the alpha-emitter 223Ra: adjuvant or alternative to conventional modalities? Clin Cancer Res (2006) 12(20 Pt 2):6250s-7s. doi:10.1158/1078-0432.CCR-06-0841

49. Sjogreen K, Ljungberg M, Strand SE. An activity quantification method based on registration of CT and whole-body scintillation camera images, with application to 131I. J Nucl Med (2002) 43(7):972-82.

50. Chouin N, Bardies M. Alpha-particle microdosimetry. Curr Radiopharm (2011) 4(3):266-80. doi:10.2174/1874471011104030266

51. Rossi HH, Rosenzweig W. A device for the measurement of dose as a function of specific ionization. Radiology (1955) 64(3):404-11. doi:10.1148/64.3.404

52. Kassis AI, Harris CR, Adelstein SJ, Ruth TJ, Lambrecht R, Wolf AP. The in vitro radiobiology of astatine-211 decay. Radiat Res (1986) 105(1):27-36. doi: $10.2307 / 3576722$

53. Raju MR, Eisen Y, Carpenter S, Inkret WC. Radiobiology of alpha particles. III. Cell inactivation by alpha-particle traversals of the cell nucleus. Radiat Res (1991) 128(2):204-9. doi:10.2307/3578139

54. Walicka MA, Vaidyanathan G, Zalutsky MR, Adelstein SJ, Kassis AI. Survival and DNA damage in Chinese hamster V79 cells exposed to alpha particles emitted by DNA-incorporated astatine-211. Radiat Res (1998) 150(3):263-8. doi: $10.2307 / 3579974$

55. Barendsen GW. Impairment of the proliferative capacity of human cells in culture by alpha-particles with differing linear-energy transfer. Int J Radiat Biol Relat Stud Phys Chem Med (1964) 8:453-66. doi:10.1080/09553006414550561

56. Barendsen GW, Beusker TL. Effects of different ionizing radiations on human cells in tissue culture. I. Irradiation techniques and dosimetry. Radiat Res (1960) 13:832-40. doi:10.2307/3570858

57. Barendsen GW, Beusker TL, Vergroesen AJ, Budke L. Effects of different radiations on human cells in tissue culture. II. Biological experiments. Radiat Res (1960) 13:841-9. doi:10.2307/3570859

58. Barendsen GW, Walter HM. Effects of different ionizing radiations on human cells in tissue culture. IV. Modification of radiation damage. Radiat Res (1964) 21:314-29. doi:10.2307/3571569

59. Barendsen GW, Walter HM, Fowler JF, Bewley DK. Effects of different ionizing radiations on human cells in tissue culture. III. Experiments with cyclotronaccelerated alpha-particles and deuterons. Radiat Res (1963) 18:106-19. doi:10. 2307/3571430

60. Raju MR, Eisen Y, Carpenter S, Jarrett K, Harvey WF. Radiobiology of alpha particles. IV. Cell inactivation by alpha particles of energies $0.4-3.5 \mathrm{MeV}$. Radiat Res (1993) 133(3):289-96. doi:10.2307/3578212

61. Eccles LJ, O'Neill P, Lomax ME. Delayed repair of radiation induced clustered DNA damage: friend or foe? Mutat Res (2011) 711(1-2):134-41. doi:10.1016/j. mrfmmm.2010.11.003

62. Gulston M, de Lara C, Jenner T, Davis E, O’Neill P. Processing of clustered DNA damage generates additional double-strand breaks in mammalian cells postirradiation. Nucleic Acids Res (2004) 32(4):1602-9. doi:10.1093/nar/gkh306

63. Pouget JP, Navarro-Teulon I, Bardies M, Chouin N, Cartron G, Pelegrin A, et al Clinical radioimmunotherapy - the role of radiobiology. Nat Rev Clin Oncol (2011) 8(12):720-34. doi:10.1038/nrclinonc.2011.160

64. Fowler JF. Radiobiological aspects of low dose rates in radioimmunotherapy. Int J Radiat Oncol Biol Phys (1990) 18(5):1261-9. doi:10.1016/0360-3016(90) 90467-X

65. Hernandez MC, Knox SJ. Radiobiology of radioimmunotherapy: targeting CD20 B-cell antigen in non-Hodgkin's lymphoma. Int J Radiat Oncol Biol Phys (2004) 59(5):1274-87. doi:10.1016/j.ijrobp.2004.02.065

66. Paillas S, Boudousq V, Piron B, Kersual N, Bardies M, Chouin N, et al. Apoptosis and p53 are not involved in the anti-tumor efficacy of (1)(2)(5)I-labeled 
monoclonal antibodies targeting the cell membrane. Nucl Med Biol (2013) 40(4):471-80. doi:10.1016/j.nucmedbio.2013.02.001

67. Williams JA, Edwards JA, Dillehay LE. Quantitative comparison of radiolabeled antibody therapy and external beam radiotherapy in the treatment of human glioma xenografts. Int J Radiat Oncol Biol Phys (1992) 24(1):111-7. doi:10.1016/0360-3016(92)91029-M

68. Alper T. Lethal mutations and cell death. Phys Med Biol (1963) 66:365-85. doi:10.1088/0031-9155/8/4/301

69. Haimovitz-Friedman A, Kan CC, Ehleiter D, Persaud RS, McLoughlin M, Fuks $\mathrm{Z}$, et al. Ionizing radiation acts on cellular membranes to generate ceramide and initiate apoptosis. J Exp Med (1994) 180(2):525-35. doi:10.1084/jem.180.2.525

70. Hanot M, Hoarau J, Carriere M, Angulo JF, Khodja H. Membrane-dependent bystander effect contributes to amplification of the response to alpha-particle irradiation in targeted and nontargeted cells. Int J Radiat Oncol Biol Phys (2009) 75(4):1247-53. doi:10.1016/j.ijrobp.2009.07.014

71. Jain MR, Li M, Chen W, Liu T, de Toledo SM, Pandey BN, et al. In vivo space radiation-induced non-targeted responses: late effects on molecular signaling in mitochondria. Curr Mol Pharmacol (2011) 4(2):106-14. doi:10.2174/ 1874467211104020106

72. Pouget JP, Santoro L, Raymond L, Chouin N, Bardies M, Bascoul-Mollevi C, et al. Cell membrane is a more sensitive target than cytoplasm to dense ionization produced by auger electrons. Radiat Res (2008) 170(2):192-200. doi:10.1667/RR1359.1

73. Valerie K, Yacoub A, Hagan MP, Curiel DT, Fisher PB, Grant S, et al. Radiationinduced cell signaling: inside-out and outside-in. Mol Cancer Ther (2007) 6(3):789-801. doi:10.1158/1535-7163.MCT-06-0596

74. Yang G, Wu L, Chen S, Zhu L, Huang P, Tong L, et al. Mitochondrial dysfunction resulting from loss of cytochrome $\mathrm{c}$ impairs radiation-induced bystander effect. Br J Cancer (2009) 100(12):1912-6. doi:10.1038/sj.bjc.6605087

75. Demaria S, Formenti SC. Radiotherapy effects on anti-tumor immunity: implications for cancer treatment. Front Oncol (2013) 3:128. doi:10.3389/fonc.2013. 00128

76. Formenti SC, Demaria S. Combining radiotherapy and cancer immunotherapy: a paradigm shift. J Natl Cancer Inst (2013) 105(4):256-65. doi:10.1093/jnci/ djs629

77. Lorimore SA, Rastogi S, Mukherjee D, Coates PJ, Wright EG. The influence of p53 functions on radiation-induced inflammatory bystander-type signaling in murine bone marrow. Radiat Res (2013) 179(4):406-15. doi:10.1667/RR3158.2

78. Boerman OC, van Schaijk FG, Oyen WJ, Corstens FH. Pretargeted radioimmunotherapy of cancer: progress step by step. J Nucl Med (2003) 44(3):400-11.

79. Goldenberg DM, Sharkey RM. Advances in cancer therapy with radiolabeled monoclonal antibodies. Q J Nucl Med Mol Imaging (2006) 50(4):248-64.

80. Goodwin DA, Meares CF, McCall MJ, McTigue M, Chaovapong W. Pre-targeted immunoscintigraphy of murine tumors with indium-111-labeled bifunctional haptens. J Nucl Med (1988) 29(2):226-34.

81. Lesch HP, Kaikkonen MU, Pikkarainen JT, Yla-Herttuala S. Avidin-biotin technology in targeted therapy. Expert Opin Drug Deliv (2010) 7(5):551-64. doi: $10.1517 / 17425241003677749$
82. Chang CH, Sharkey RM, Rossi EA, Karacay H, McBride W, Hansen HJ, et al. Molecular advances in pretargeting radioimunotherapy with bispecific antibodies. Mol Cancer Ther (2002) 1(7):553-63.

83. Pagel JM, Kenoyer AL, Back T, Hamlin DK, Wilbur DS, Fisher DR, et al. Anti-CD45 pretargeted radioimmunotherapy using bismuth-213: high rates of complete remission and long-term survival in a mouse myeloid leukemia xenograft model. Blood (2011) 118(3):703-11. doi:10.1182/blood-2011-04347039

84. Park SI, Shenoi J, Pagel JM, Hamlin DK, Wilbur DS, Orgun N, et al. Conventional and pretargeted radioimmunotherapy using bismuth-213 to target and treat non-Hodgkin lymphomas expressing CD20: a preclinical model toward optimal consolidation therapy to eradicate minimal residual disease. Blood (2010) 116(20):4231-9. doi:10.1182/blood-2010-05-282327

85. Zhang M, Zhang Z, Garmestani K, Schultz J, Axworthy DB, Goldman CK, et al. Pretarget radiotherapy with an anti-CD25 antibody-streptavidin fusion protein was effective in therapy of leukemia/lymphoma xenografts. Proc Natl Acad Sci USA (2003) 100(4):1891-5. doi:10.1073/pnas.0437788100

86. Frost SH, Back T, Chouin N, Hultborn R, Jacobsson L, Elgqvist J, et al. Comparison of (211)At-PRIT and (211)At-RIT of ovarian microtumors in a nude mouse model. Cancer Biother Radiopharm (2013) 28(2):108-14. doi:10.1089/cbr.2012. 1281

87. Elgqvist J, Andersson H, Back T, Claesson I, Hultborn R, Jensen H, et al. Fractionated radioimmunotherapy of intraperitoneally growing ovarian cancer in nude mice with 211At-MX35 F(ab')2: therapeutic efficacy and myelotoxicity. Nucl Med Biol (2006) 33(8):1065-72. doi:10.1016/j.nucmedbio.2006.07.009

88. Jackson MR, Falzone N, Vallis KA. Advances in anticancer radiopharmaceuticals. Clin Oncol (2013) 25(10):604-9. doi:10.1016/j.clon.2013.06.004

89. Das T, Pillai MR. Options to meet the future global demand of radionuclides for radionuclide therapy. Nucl Med Biol (2013) 40(1):23-32. doi:10.1016/j. nucmedbio.2012.09.007

Conflict of Interest Statement: The authors declare that the research was conducted in the absence of any commercial or financial relationships that could be construed as a potential conflict of interest.

Received: 07 June 2013; paper pending published: 26 July 2013; accepted: 19 December 2013; published online: 14 January 2014.

Citation: Elgqvist J, Frost S, Pouget J-P and Albertsson P (2014) The potential and hurdles of targeted alpha therapy - clinical trials and beyond. Front. Oncol. 3:324. doi: 10.3389/fonc.2013.00324

This article was submitted to Radiation Oncology, a section of the journal Frontiers in Oncology.

Copyright (c) 2014 Elgqvist, Frost, Pouget and Albertsson. This is an open-access article distributed under the terms of the Creative Commons Attribution License (CC BY). The use, distribution or reproduction in other forums is permitted, provided the original author(s) or licensor are credited and that the original publication in this journal is cited, in accordance with accepted academic practice. No use, distribution or reproduction is permitted which does not comply with these terms. 